\title{
VARIATIONS IN SALINITY TOLERANCE OF SELECTED MANGO ROOTSTOCKS
}

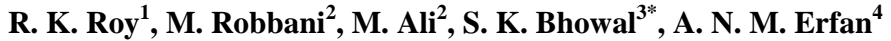 \\ ${ }^{1 \& 4}$ M.S. Student in Horticulture, Patuakhali Science and Technology University, Bangladesh \\ ${ }^{2}$ Professor, Department of Horticulture, Patuakhali Science and Technology University, Bangladesh \\ ${ }^{3}$ Scientific Officer (Agronomy), On-Farm Research Division, Bangladesh Agricultural Research Ins., Noakhali, Bangladesh \\ *Corresponding author: shamal.bau@gmail.com
}

Key words: Mango rootstock, salinity tolerance

\begin{abstract}
An experiment was conducted at the Germplasm Centre, Department of Horticulture, Patuakhali Science and Technology University (PSTU) during the period from July 2011 to March 2013 to study the performance of selected mango rootstocks in the saline area in Bangladesh. The experiment consisted of four mango rootstock lines collected from Rangpur, Dumki, Khulna and Kuakata, and five salinity treatments namely control $\left(0 \mathrm{dSm}^{-1}\right)$, low $\left(4 \mathrm{dSm}^{-1}\right)$, medium $\left(6 \mathrm{dSm}^{-1}\right)$, high $\left(8 \mathrm{dSm}^{-1}\right)$ and very high $\left(10 \mathrm{dSm}^{-1}\right)$. A two factor experiment was conducted in a Randomized Complete Block Design (factorial) with four replications. Results revealed that rootstock line and salinity levels had significant influences on various crop characters viz. length of rootstocks, diameter of rootstocks, number of leaves and percent rootstocks success and survivability. In case of rootstocks, the longest rootstock length $(41.38 \mathrm{~cm})$, highest number of leaves (37.58) and survivability (71.73\%) were recorded in Rangpur line. In case of salinity treatments, rootstock diameter (16.09 mm), number of leaves/graft (36.47) and survivability (67.37\%) were recorded in low salinity treatment. Interaction of rootstock lines and different salinity treatments showed significant variation on the length and diameter of rootstocks at 120 DAT. The maximum diameter of rootstock $(17.63 \mathrm{~mm})$ was recorded in high $\left(8 \mathrm{dSm}^{-1}\right)$ salinity treatment in rootstock line of Kuakata, followed by the same stages of rootstock lines of Khulna $(17.56 \mathrm{~mm})$. The longest rootstock $(46.75 \mathrm{~cm})$ was recorded in control treatment $\left(0 \mathrm{dSm}^{-1}\right)$ with rootstock line of Rangpur followed by the same stages of rootstock $(41.75 \mathrm{~cm})$ with medium salinity treatment $\left(6 \mathrm{dSm}^{-1}\right)$. Rangpur rootstock line performed best from $0-8 \mathrm{dSm}^{-1}$ salinity. The overall salinity tolerance was graded as follows: Rangpur rootstock line > Dumki rootstock line > Kuakata rootstock line $>$ Khulna rootstock line.
\end{abstract}

\section{Introduction}

Mango (Mangifera indica L.) is one of the most popular and commercially important fruits in Bangladesh which is known as the "King of tropical fruits". It belongs to the family Anacardiaceae which is believed to have originated in the Eastern India, Assam, Burma or in the Malayan region (Mukherjee, 1997). It has been cultivated in this sub-continent from 4000 years ago (Candole, 1984). Mango is grown in wide geographical area particularly in India, Pakistan, Brazil, Mexico, the Philippines, Indonesia, Thailand and SriLanka. In Bangladesh mangoes are grown everywhere, but the commercial and good quality grafted mangoes grown in the north-western districts and unknown varieties (seedling mangoes) are grown in the south eastern and other part of the country (Bhuyan, 1995). Mango ranks third among the tropical fruits grown in the world with the total production of 28848 thousand metric tons (FAO, 2002). In Bangladesh it ranks first in terms of area and third in production. It occupies an area of about 51.01 thousand hectares, with the production of 243 thousand metric tons of fruits (BBS, 2004).

In Bangladesh, a general decreasing trend in area and production of mango is observing during 1994-95 to 2003-04 (BBS, 2004). Because, about 90\% existing mango plants are raised from seeds which are mostly tall in nature with a large canopy (Hossain, 1994). Thus, it is difficult to incorporate tall and large sized mango varieties in limited area. These are the major reasons of diminishing mango production area. 
Roy et al.

The other reasons behind this are lack of suitable variety (Sarder et al., 1995), unavailability of suitable planting materials etc. Grafted mango plants are true-to-type, require less area and start bearing earlier than the plants raised from seed. Now a day's using of epicotyle grafting in mango is a practice with good success for rapid multiplication of mango. At present, scion with the same polythene strip is used for graft joint. But research findings on these aspects in Bangladesh are very limited or scanty.

Various factors influence the success and survivability of mango graft, viz. time of operation, grafting method, defoliation period of scion, maturity of stock and scion, wrapping technique of scion, leaf retention on rootstock and variety etc. Among these, physiological maturity of stock and scion wood are very important factors for higher success, survivability and growth of grafts (Kains and Mc Question, 1958; Brahmachare et al., 1999).

The information or research work with mango in saline area of southern belt is very limited. Mango production is hampered due to restricted growth of the plant, root expansion hampered, low success and survivability due to high salinity. Considering the above facts the present research work was undertaken to study the salinity tolerance of selected mango rootstocks.

\section{Materials and Methods}

The experiment was conducted at the Germplasm Centre, department of Horticulture, Patuakhali Science and Technology University (PSTU), during the period from July 2011 to March 2013. The experimental area was situated under the sub-tropical monsoon climate, which is characterized by high temperature and heavy rainfall during the months of July to September and scantly rainfall associated with moderate low temperature during the rest period of the year. The soil of the experimental area was silty loam in texture belonging to the Gangas Flood Plain of AEZ 13 having non-calcareous dark grey flood plain soil. The selected area was a medium high land. It was fertile, well drained and slightly acidic with the $\mathrm{pH}$ varying from 5.5 to 6.8 (BARC, 1989). The experiment consisted of two factors i.e. Factor-A: four type of mango rootstocks viz. $\mathrm{R}_{1}=$ Rangpur line, $\mathrm{R}_{2}=$ Khulna line, $\mathrm{R}_{3}=$ Dumki line, $\mathrm{R}_{4}=$ Kuakata line and Factor- $\mathrm{B}$ : five level of soil salinity viz. $\mathrm{S}_{0}=$ Control $\left(0 \mathrm{dSm}^{-1}\right), \mathrm{S}_{1}=\operatorname{Low}\left(4 \mathrm{dSm}^{-1}\right), \mathrm{S}_{2}=$ Medium $\left(6 \mathrm{dSm}^{-1}\right), \mathrm{S}_{3}=$ High $\left(8 \mathrm{dSm}^{-1}\right), \mathrm{S}_{4}=$ Very high $\left(10 \mathrm{dSm}^{-1}\right)$. A two factor experiment was conducted in a Factorial Randomized Complete Block Design with four replications. Healthy and heavy stones of mango fruits of unknown cultivars were collected and placed in a bucket of water. Only those stones that sunk and touched the bottom of bucket (containing water) were selected. About 1000 stones were selected for this process, which were uniform in size and shape. The stones were placed in polybags containing a mixture of soil and cowdung at the ratio of 1:1. One stone was placed in one polybag. After placing the seeds were germinated within 15 to 30 days. The experimental pots were made by earthen, containing 2-3 aeration holes at bottom for removal of excess water. Total 480 experimental pots were filled by soil; well decompose cowdung, sand \& small pitches of broken stones at the ratio of 1:1:1:1. Nearly one and a half year mango rootstocks collected from four different types of mango cultivar which were raised in polybags previously \& transplanted to the experimental pots. The healthy, vigorous, uniform in size and growth, pest and disease free rootstocks was selected for the experiment. Pots containing healthy and uniform size rootstocks were raised in each rootstock line. Intercultural operations like irrigation, weeding, application of fertilizer, spraying of insecticides and fungicide were given whenever needed for the good health of stock plant. Four different rootstock lines were collected from Rangpur, Dumki, Kuakata and Khulna region. At first rootstocks were separated from different types of rootstock by their proper identity through individual tagging. Four rootstock lines were arranged according to their identical number for properly data collection as well as performance review of different rootstock lines. All necessary measures were adopted to make the pot free from weeds and create a favorable environment to ensure proper growth and development of grafted plants. Weeding and mulching were done whenever necessary during the period of investigation. The channels, made around each pot were connected to the main drain for rapid removal of excess rain water. Proper shades were provided with the help of bamboo and coconut leaf until the grafts were in good condition in growth. Sometimes the shade was removed to 
Salinity Tolerance of Mango Rootstocks

expose the plant to the direct sunlight for their proper growth. As a preventive measure against insect, pest and disease, spraying with insecticide and fungicides were done following a routine schedule. For this, Diazinon and Diathane M-45 @ 2ml liter ${ }^{-1}$ of water were applied at 7-10 days interval from 2-3 weeks after grafting and continued up to the last date of recording final data. The means of all the treatments were calculated and compared by Least Significant Difference (LSD) test at 5\% level of probability (Gomez and Gomez, 1984).

\section{Results and Discussion}

\section{Effect of rootstock}

Significant variation was noticed in the growth of rootstocks from 30 to 120 days after transplanting (Table 1). At 30 DAS, Rangpur and Khulna rootstock was similar and higher than the rest. Similar trend was recorded at 60 DAT and 90 DAT. There was trend to increase length with the advancement of days. The longest length of rootstock was found in Rangpur rootstock line $(41.38 \mathrm{~cm})$ while the shortest length of rootstock found in Kuakata rootstock line $(34.25 \mathrm{~cm})$ at 120 days after transplanting. Significant variation was also noticed in the number of new leaves from 30 to 120 days after transplanting (Table 1). Number of leaves showed maximum at Khulna line followed by Rangpur at 30 DAT. Similar trend was found at 60 and 90 DAT but there were no significant difference at 90 and 120 DAT. After initial success, the rootstocks were observed for 120 days, some rootstock died during this period. At the end of 120 days, the percentage of rootstock survival was recorded and the percentage of rootstock survival was presented in Table 1. The highest rootstock survival (71.73\%) was obtained from Rangpur rootstock line while other rootstock survivability among the lines were similar.

Table 1. Main effect of rootstock lines on the length of rootstocks, leaves number and rootstock survivability at different days after transplanting

\begin{tabular}{|c|c|c|c|c|c|c|c|c|c|}
\hline \multirow{2}{*}{$\begin{array}{l}\text { Rootstock } \\
\text { line }\end{array}$} & \multicolumn{4}{|c|}{ Rootstock length (cm) } & \multicolumn{4}{|c|}{ No. of leaves } & \multirow{2}{*}{$\begin{array}{c}\text { Rootstock } \\
\text { survivability at } \\
120 \text { DAT (\%) }\end{array}$} \\
\hline & 30 days & 60 days & 90 days & 120 days & 30 days & 60 days & 90 days & 120 days & \\
\hline Rangpur & $39.50 a$ & 40.10a & $40.53 a$ & $41.38 \mathrm{a}$ & 22.38ab & 24.85ab & 31.77 & 37.58 & 71.73a \\
\hline Dumki & $32.95 b$ & $33.40 \mathrm{~b}$ & $33.78 b$ & $34.63 b$ & $15.99 b$ & $19.80 \mathrm{~b}$ & 24.27 & 27.02 & $60.90 \mathrm{~b}$ \\
\hline Khulna & $36.67 a$ & 36.97ab & 37.28ab & 37.97ab & 25.33a & $28.35 a$ & 31.52 & 33.70 & $57.39 \mathrm{~b}$ \\
\hline Kuakata & $32.90 \mathrm{~b}$ & $33.25 b$ & $33.58 b$ & $34.25 b$ & $16.05 b$ & $18.42 \mathrm{~b}$ & 25.08 & 28.40 & $56.73 b$ \\
\hline $\operatorname{LSD}_{(0.05)}$ & 3.57 & 3.74 & 3.72 & 3.74 & 8.014 & 8.24 & NS & NS & 4.89 \\
\hline CV (\%) & 7.18 & 7.42 & 7.31 & 7.20 & 28.71 & 25.75 & 26.85 & 23.91 & 5.66 \\
\hline
\end{tabular}

\section{Effect of salinity}

Significant variation was found among different salinity treatments in the present experiment (Table 2). There was no significant difference in salinity treatment at 30 DAT except very high salinity level. Similar trend was followed upto 120 DAT. But maximum length of rootstock $(39.72 \mathrm{~cm})$ was recorded at high salinity level while shortest rootstock $(33.81 \mathrm{~cm})$ was observed in very high $\left(10 \mathrm{dSm}^{-1}\right)$ salinity treatment at 120 DAT (Table 2). Very high salinity treatment lowered the water potential of the roots, and this caused quick reductions in growth rate along with a suite of metabolic changes identical to those caused by water stress. The effect of salinity treatments on the diameter of rootstocks has been shown in the Fig. 1. Significant variation was found different salinity treatments. After 120 DAT, high salinity treatments was found maximum diameter of rootstock $(16.09 \mathrm{~mm})$ while the lowest diameter of rootstock in very high $\left(10 \mathrm{dSm}^{-1}\right)$ salinity treatment $(13.52 \mathrm{~mm})$ (Fig. 1). Significant variation was found different salinity treatments on the rootstock survivability in the experiment but number of leaves plant ${ }^{-1}$ was not significantly influenced by salinity treatment. Rootstock survivability (\%) was minimum at low level of 
Roy et al.

salinity followed by control. Srivastava et al. (1989) also reported that increases the salinity treatment decreases the rate of survivability of mango.

Table 2. Main effect salinity treatment on the length of rootstocks, leaves number and rootstock survivability at different days after transplanting

\begin{tabular}{|c|c|c|c|c|c|c|c|c|c|}
\hline \multirow{2}{*}{$\begin{array}{l}\text { Salinity } \\
\text { treatment }\end{array}$} & \multicolumn{4}{|c|}{ Rootstock length $(\mathrm{cm})$} & \multicolumn{4}{|c|}{ No. of leaves } & \multirow{2}{*}{$\begin{array}{l}\text { Rootstock } \\
\text { survivability } \\
\text { (\%) }\end{array}$} \\
\hline & 30 days & 60 days & 90 days & 120 days & 30 days & 60 days & 90 days & 120 days & \\
\hline Control & 34.91ab & 35.59ab & 35.91ab & 36.78ab & 19.44 & 23.22 & 28.78 & 32.81 & 64.77ab \\
\hline & 36.9 & 37.3 & $37.72 \mathrm{a}$ & $38.47 a$ & 20.56 & 24.09 & 33. & 36.47 & \\
\hline Medium & $35.06 \mathrm{ab}$ & $35.44 a b$ & 35.91ab & $36.50 \mathrm{ab}$ & 17.59 & 20.56 & 25.69 & 28.66 & $9 \mathrm{bc}$ \\
\hline High & $38.13 a$ & $38.59 a$ & $38.91 a$ & $39.72 \mathrm{a}$ & 21.61 & 24.72 & 28.06 & 31.25 & $59.64 c$ \\
\hline Very high & $32.47 \mathrm{~b}$ & $32.69 \mathrm{~b}$ & $33.00 \mathrm{~b}$ & $33.81 \mathrm{~b}$ & 20.47 & 21.69 & 25.19 & 29.19 & $55.97 \mathrm{c}$ \\
\hline $\operatorname{LSD}_{(0.05)}$ & 3.57 & 3.74 & 3.72 & 3.74 & NS & NS & NS & NS & 4.89 \\
\hline CV (\%) & 7.18 & 7.42 & 7.31 & 7.20 & 28.71 & 25.75 & 26.85 & 23.91 & 5.66 \\
\hline
\end{tabular}

Control $=0 \mathrm{dSm}^{-1}$, low $=4 \mathrm{dSm}^{-1}$, medium $=6 \mathrm{dSm}^{-1}$, high $=8 \mathrm{dSm}^{-1}$, very high $=10 \mathrm{dSm}^{-1}$

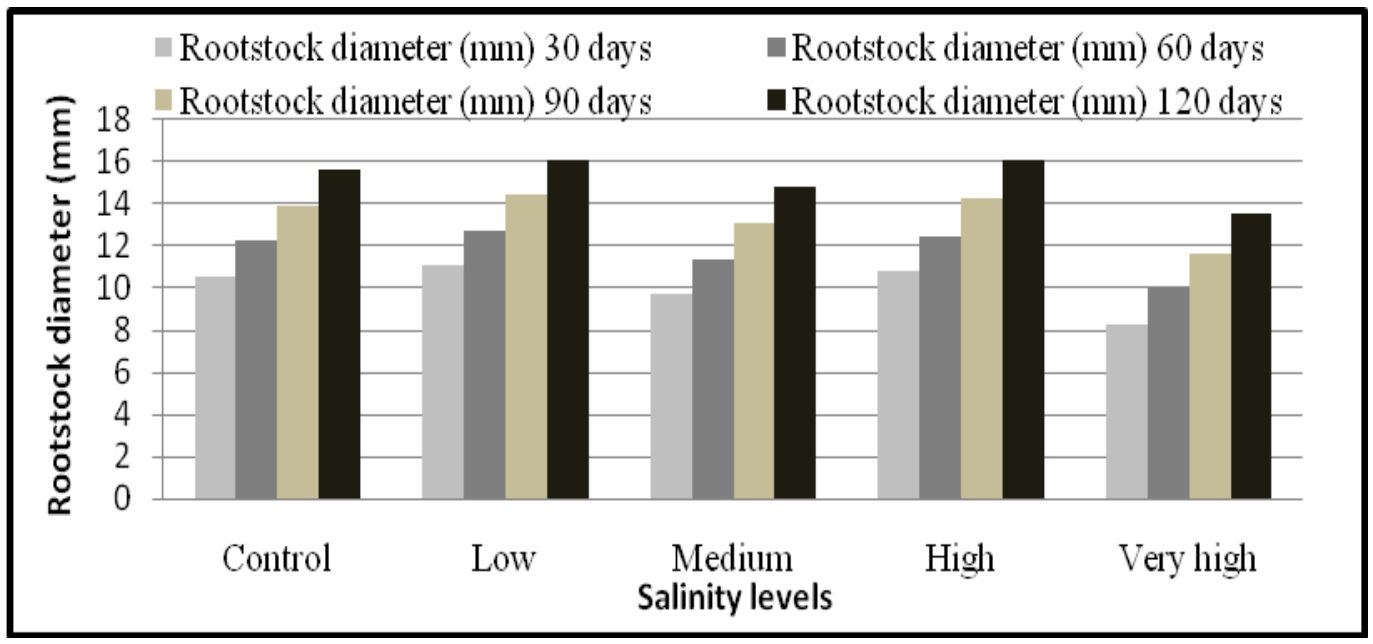

Fig. 1. Effect of salinity treatments on the diameter of rootstocks at different days after transplanting

\section{Interaction effect of rootstocks and salinity}

Interaction of rootstock lines and different salinity treatments showed significant variation on the length of rootstocks at 120 DAT (Fig. 2). The periodical data showed that more increase in length of rootstocks recorded at 120 DAT. The Longest rootstock $(46.75 \mathrm{~cm})$ was recorded when control salinity treatment $(0$ $\left.\mathrm{dSm}^{-1}\right)$ with rootstock line of Rangpur followed by the same stages of rootstock $(41.75 \mathrm{~cm})$ with medium salinity treatment $(6 \mathrm{dSm}-1)$. The shortest rootstock $(29.88 \mathrm{~cm})$ was recorded in the rootstock line of Kuakata with very high salinity $\left(10 \mathrm{dSm}^{-1}\right)$ treatment (Fig. 2). 


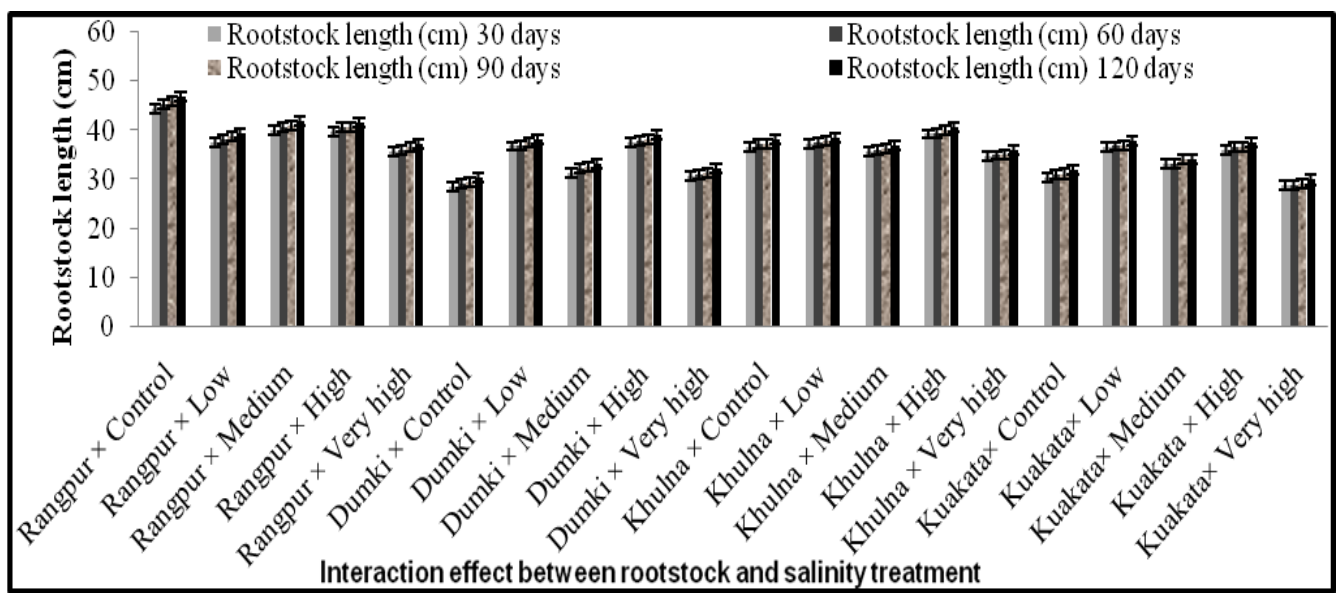

Fig. 2. Interaction of rootstocks and salinity treatments on the rootstock length at different DAT

Interaction of rootstock lines and salinity treatment had significant influence on the diameter of rootstock at 120 DAT (Fig. 3). There was trend to increase rootstock diameter with the advancement of days 30 to 120 DAT. The maximum diameter of rootstock $(17.63 \mathrm{~mm})$ was recorded in high $\left(8 \mathrm{dSm}^{-1}\right)$ salinity treatment into the rootstock line of Kuakata, followed by the same stages of rootstock lines of Khulna $(17.56 \mathrm{~mm})$ with high salinity treatment (Fig. 3). The minimum diameter $(12.38 \mathrm{~mm})$ of rootstock line of Dumki was recorded with very high $\left(10 \mathrm{dSm}^{-1}\right)$ salinity treatment.

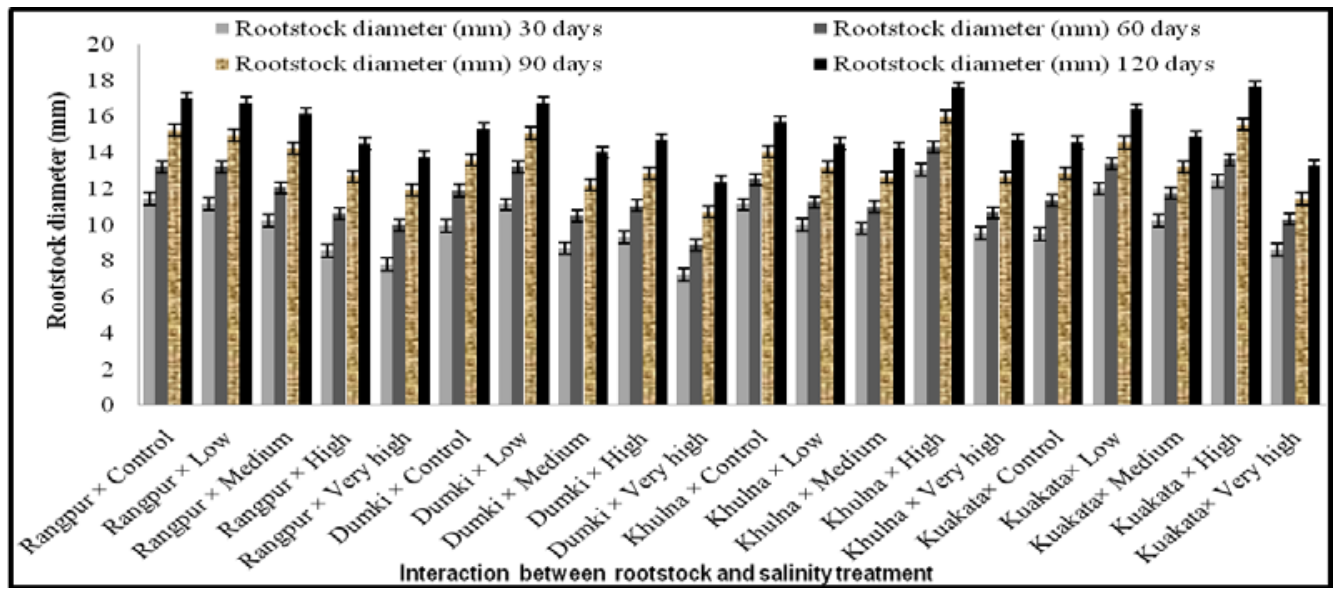

Fig. 3. Interaction of rootstocks and salinity treatments on the diameter of rootstock at different DAT

\section{References}

BARC. 1989. Fertilizer Recommendation Guide. Bangladesh Agriculture Research Concil, New Airport Road, Farmgate, Dhaka-1207. pp.11-41.

BBS. 2004. Monthly Statistical Bulletin, Bangladesh Bureau of Statistics, Statistics Division, Ministry of Planning, Government of the People’s Republic of Bangladesh. Dhaka, p.49.

Brahmachari, V. S., A. R. Singh and R. C. Bishwas. 1999. Effect of period of defoliation of scion and age of rootstock on success of epicotyl grafting in mango (Mangifera indica L.) cv. Amrapali. Orissa J. Hort. 27: 1-4. 
Roy et al.

Bhuyan, M. A. J. 1995. Mango. In: Fruit production Manual, Horticulture Research and Development Project, DAE-PADC. p.197.

Candole, A. D. 1984. Origin of Cultivated Plants. Vegal Paul Trench and Co., London pp.1-67.

FAO. 2002. Production Yearbook. Statistical Series No. 163. Food and Agriculture Organization, Rome, Italy, p.182.

Hossain, A. K. M. A. 1994. Production Technology of Mango. Horticulture Research Centre, BARI, Joydebpur, Gazipur. 122p.

Kains, M. G. and M. McQuestion. 1958. Propagation of Plants. Grage Judd Publishing Company, Inc., New York. p.225.

Mukherjee, K. U. 1997. Introduction: Botany and importance. In: The Mango: Botany, Production and Uses. $1^{\text {st }}$ edition (R. \& Litz Ed.), CAB International, Wallingford, UK. pp.1-19.

Sarder, P. K., D. Guha and M. A. Uddin. 1995. Assessment of introduced mango germplasm under Bangladesh condition. Annual Report on Mango Improvement, Regional Horticulture Research Station, BARI, Nawabganj-6300, Bangladesh. p.10.

Srivastava, K. C., N. P. Singh, M. S. Rajput, G. C. Sinha and B. Lai. 1989. Performance of mango plants raised by different methods. Acta Hort. 231: 209- 297. 